\title{
ПАРАМЕТРЫ ПЛОДОНОШЕНИЯ И СОДЕРЖАНИЕ ФЛАВОНОИДОВ И АСКОРБИНОВОЙ КИСЛОТЫ В ПЛОДАХ ГОЛУБИКИ (VACCINIUM)
}

\author{
() С.В. Мухаметова ${ }^{* 1}$, Е.А. Скочилова ${ }^{2}$, Д.В. Протасов ${ }^{2}$ \\ ${ }^{1}$ Ботанический сад-институт Поволжского государственного \\ технологического университета, ул. Мира, 2Б, Йошкар-Ола, 424030 \\ (Россия), e-mail: MuhametovaSV@volgatech.net \\ ${ }^{2}$ Марийский государственный университет, ул. Осипенко, 60, Йошкар-Ола \\ (Россия), e-mail: skochilova@inbox.ru
}

\begin{abstract}
Приведены результаты исследований параметров плодоношения и содержания в плодах флавоноидов и аскорбиновой кислоты видов и сортов голубики (Vaccinium) в условиях Республики Марий Эл. Объектами исследования стали $V$. uliginosum L., $V$. angustifolium Ait., 8 сортов $V$. corymbosum L., а также $V . a . \times V$. c. Northcountry. Значения диаметра плодов голубики в годы исследования варьировали от 6,4 до 13,1 мм, длины - от 6,5 до 10,3 мм, массы 100 плодов - 24,6 до 113,9 г. Изученные виды и сорта разделены на 2 группы: с крупными плодами - V. c. Patriot, $V$. c. Nelson, $V . c$. Toro, $V . c$. Duke, $V . c$. Bluegold, $V$. c. Bluecrop; с мелкими плодами $-V$. uliginosum, $V . c . \times V$. $a$. Northcountry, $V . c$. Earlyblue, $V$. c. Rancocas, $V$. angustifolium. Большинство изученных голубик характеризуются меньшими размерами и массой плодов по сравнению с литературными данными. Содержание биологически активных веществ в плодах Vaccinium оставалось на высоком уровне. Диапазон содержания (мг/100 г сырой массы) рутина составил от 1,79 до 4,53 , антоцианов - от 18,1 до 78,2, аскорбиновой кислоты - от 9,07 до 29,9. Наибольшее количество рутина выявлено у $V$. uliginosum, антоцианов - у $V$. angustifolium, аскорбиновой кислоты - у $V . c . \times V$. a. Northcountry. Copт $V . c$. Patriot содержал наименьшее количество биохимических соединений.

Ключевые слова: голубика, Vaccinium, плодоношение, флавоноиды, аскорбиновая кислота.
\end{abstract}

\section{Введение}

Особое место среди нетрадиционных плодово-ягодных культур занимает голубика - представитель семейства Вересковые (Ericaceae Juss.). В Северной Америке и Европе голубика широко распространена в культуре и выращивается в промышленных масштабах [1-7]. Возделывание ее начинается в странах бывшего СССР [8-11], а также в России [12, 13].

Данная культура не является фармакопейным видом, но широко используется в народной медицине. Ягоды голубики - источник ценных пищевых и биологически активных веществ различного фармакологического действия. Фенольные соединения, содержащиеся в ягодах голубики, являются уникальными вторичными метаболитами. Одним из самых больших классов фенольных соединений являются флавоноиды. В плодах голубики содержится гликозид кверцетина - рутин, широко используемый в медицине как капилляроукрепляющее средство. Поэтому прием ягод голубики полезен при атеросклерозе, гипертонии, ангине и других заболеваниях, сопровождающихся недостаточностью капиллярного кровообращения.

Основными красящими веществами растений являются антоцианы, которые находятся, как правило, в виде гликозидов и локализованы в вакуолях. Антоцианы улучшают строение волокон и клеток соедини-

Мухаметова Светлана Валерьевна - инженер, тел. (8362) 68-29-15, e-mail: MuhametovaSV@volgatech.net Скочилова Елена Анатольевна - доцент, кандидат биологических наук, тел. (8362) 68-79-00, e-mail: skochilova@inbox.ru

Протасов Дмитрий Валентинович - студент, e-mail: protasovdv@yandex.ru тельной ткани, оказывают бактерицидное действие. Полезные свойства антоцианов используются в медицине при производстве различных биологических добавок.

Фенольные соединения также способствуют лучшему усвоению аскорбиновой кислоты, которая

\footnotetext{
* Автор, с которым следует вести переписку.
} 
является одним из наиболее широко распространенных в природе витаминов. Она синтезируется растениями и подавляющим большинством животных, но не вырабатывается в организме человека [14], куда может поступать лишь с пищевыми продуктами в виде окисленной формы ( $L$-дегидроаскорбиновой кислоты).

Употребление витаминов и флавоноидов, находящихся в плодах растений, полезно для организма человека, так как, являясь антиоксидантами, они улучшают процессы кровообращения и способствуют укреплению иммунитета $[15,16]$. Кроме того, в медицине ягоды голубики используют как противовоспалительное, противоцинготное, общеукрепляющее, жаропонижающее, тонизирующее средство [12, 6].

Целью исследования являлось изучение показателей плодоношения и содержания флавоноидов и аскорбиновой кислоты в плодах некоторых видов и сортов Vaccinium, прошедших первичные интродукционные испытания в Ботаническом саду-институте Поволжского государственного технологического университета (БСИ ПГТУ), Йошкар-Ола, Республика Марий Эл.

\section{Экспериментальная часть}

Исследования проводили в 2015-2016 гг. В качестве объектов исследований были выбраны растения 11 таксонов рода Vaccinium коллекции БСИ ПГТУ: голубика обыкновенная (V. uliginosum L.), голубика узколистная ( $V$. angustifolium Ait.), сорта голубики высокорослой (V. corymbosum L.): Bluecrop, Bluegold, Duke, Earlyblue, Nelson, Patriot, Rancocas, Toro, а также сорт Northcountry, являющийся межвидовым гибридом (V. angustifolium $\times V$. corymbosum). Жизненная форма голубики - листопадный кустарник [12] или кустарничек, хамефит [17].

Растения поступили в коллекцию в 2005-2008 гг., таким образом, их возраст на момент исследования составил более 7-10 лет. V. angustifolium получена из Костромской лесной опытной станции, растения V. uliginosum пересажены из природных местообитаний в окрестностях Йошкар-Олы. Все изученные сорта голубики поступили из ООО «Центр медицинской, социальной и производственной адаптации» (г. Москва). Обследованные растения произрастают в экспозиции «Вересковый сад», являющейся элементом общего декоративного оформления центральной части сада [18]. Субстратом для растений голубики служит верховой торф на дренажном слое из песка и керамзита. Агротехника включает прополки, поливы в засушливый период, зимнее укрытие еловым лапником.

Плоды собирали в июле в фазу массового их созревания. В 30 кистях подсчитывали количество плодов. Размеры 30 плодов (диаметр и длину) измеряли штангенциркулем с точностью до 0,1 мм. Индекс формы определяли отношением длины плода к его диаметру. Плоды взвешивали на электронных весах SJCE VIBRA с точностью до 0,01 г, затем высушивали до воздушно-сухого состояния в электрической сушилке для овощей и фруктов ЭСОФ-0,5/220 «Ветерок» при температуре $70^{\circ} \mathrm{C}$. Отношением массы сухих плодов к массе свежесобранных находили выход воздушно-сухих плодов, выраженный в процентах.

Количественные показатели биологически активных веществ в ягодах V. uliginosum, V. angustifolium, $V$. c. Patriot, $V . c . \times V . a$. Northcountry изучали в 2015 г. Содержание рутина в плодах определяли фотометрическим методом [19] при помощи фотоэлектроколориметра КФК-2-УХЛ 4.2 (Россия). Количественный анализ антоцианов проводили спектрофотометрически на СФ-46 («ЛОМО», Россия). Концентрацию антоцианов пересчитывали на цианидин-3-глюкозид [20]. Аскорбиновую кислоту в ягодах определяли методом титрования [21].

Статистическую обработку данных проводили с использованием программы Microsoft Excel 2010 и пакета программ «Statistica 6.0». Достоверность различий определяли по распределению Стьюдента на доверительном уровне 95\%. Уровень изменчивости признака оценивали по методике Г.Н. Зайцева [22].

Территория Республики Марий Эл входит в умеренный климатический пояс, район с умереннохолодной зимой, область недостаточного увлажнения. По данным метеопоста БСИ за 1968-2010 гг., среднегодовая температура воздуха составляет $+3,6^{\circ} \mathrm{C}$. Средняя годовая сумма осадков -580 мм, в том числе 206 мм приходятся на зимний период. Продолжительность вегетационного периода составляет 175 дней, периода активной вегетации - 138 дней [23]. Поскольку голубика плодоносит на приросте предшествующего года, были проанализированы метеоданные не только 2015-2016 гг., но и 2014 г. Среднемесячные показатели периода с апреля по октябрь представлены на рисунке 1.

Согласно значениям гидротермического коэффициента Г.Т. Селянинова, условия увлажнения за период активной вегетации 2014 года были слабозасушливыми (1,10), 2015 - засушливыми (0,96), 2016 очень засушливыми $(0,64)[24]$. Следовательно, 2015 год был более благоприятным для формирования плодов голубики по сравнению с 2016 г. 


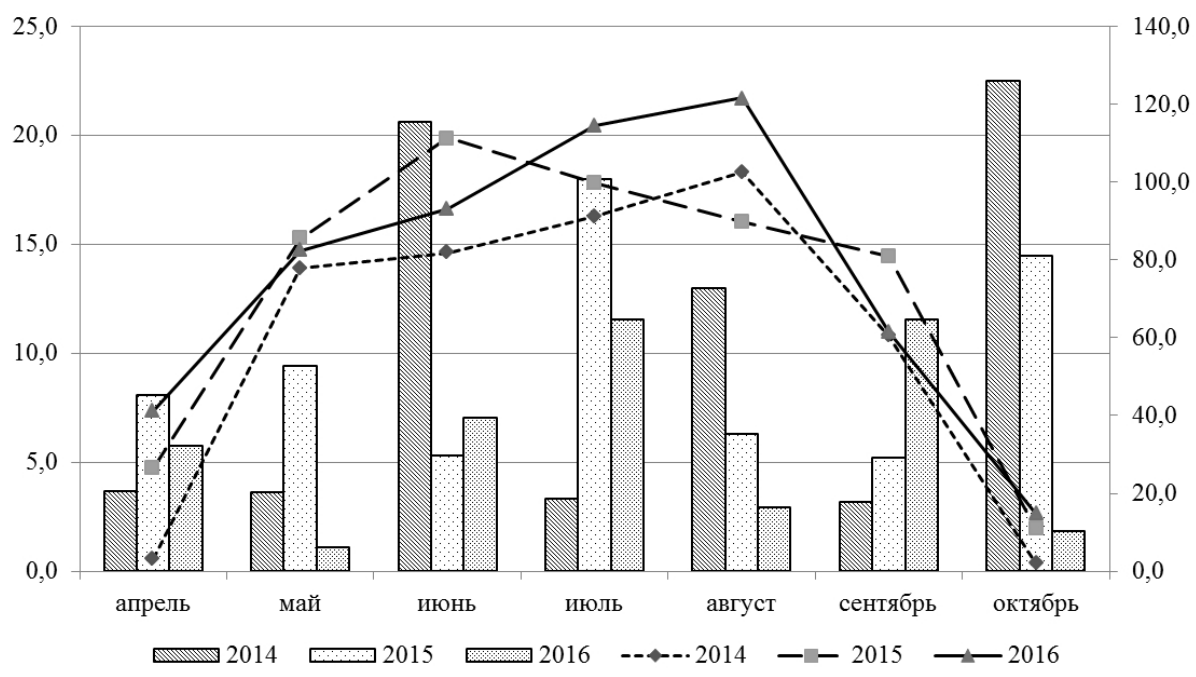

Рис. 1. Среднемесячная температура и количество осадков в апреле - октябре 2014-2016 гг.

По горизонтали - месяцы; по вертикали: слева - температура, ${ }^{\circ} \mathrm{C}$; справа - количество осадков, мм

\section{Обсуждение результатов}

В таблице представлены показатели плодоношения видов и сортов голубики.

Сопоставление значений массы плодов в годы исследования показало, что в 2016 г. в более засушливых условиях у сортов Bluecrop, Bluegold и Rancocas масса плодов была выше по сравнению с 2015 г., причем у первого сорта на статистически достоверном уровне. Напротив, у таких сортов, как Northcountry, Toro, Patriot, а также видов $V$. uliginosum и $V$. angustifolium, масса плодов уменьшилась. Различие достоверно у первых двух названных сортов. Изменения в массе плодов, вероятно, связано с различной реакцией генотипов растений на условия увлажнения. Известно, что величина плодов зависит от погодных условий и содержания влаги в почве, и недостаток почвенной влаги во второй половине лета отрицательно сказывается на созревающих плодах и на закладке генеративных почек урожая будущего года. Это связано с тем, что растения голубики имеют поверхностную корневую систему [12].

Среди изученных таксонов наибольшей массой и размерами плодов характеризовались сорта $V$. corymbosum Nelson, Patriot и Toro. В 2015 г. различие между последними двумя было статистически не значимым, в 2016 г. - значимым. Плоды $V$. uliginosum отличались наименьшей массой в оба года исследования, достоверно отличающейся от остальных обследованных таксонов в 2015 г.

Была построена дендрограмма сходства на основе массы и размеров плодов (рис. 2).

Согласно дендрограмме, среди изученных таксонов голубики выделены 2 группы: с крупными плодами - V. c. Patriot, V. c. Nelson, $V$. c. Toro, $V$. c. Duke, V. c. Bluegold, V. c. Bluecrop; с мелкими $V$. uliginosum, $V . c . \times V$. a. Northcountry, $V . c$. Earlyblue, $V . c$. Rancocas, $V$. angustifolium. По литературным данным $[12,1,5]$, плоды большинства изученных видов и сортов голубики должны быть крупнее, чем формировались в условиях БСИ ПГТУ. Очевидно, в условиях пункта интродукции растения не проявили максимальные возможности, что может быть связано с абиотическими факторами (предположительно, нехваткой почвенной влаги). Повысить продуктивность возможно улучшением агротехнических приемов увеличением поливов и внесением удобрений. Аналогичные данные получены нами и при изучении сортов брусники и клюквы, также относящихся к роду Vaccinium [25].

Изменчивость массы плодов в 2015 г. характеризовалась значительным уровнем варьирования, а в 2016 г., когда количество плодоносящих сортов увеличилось, снизилась в область «верхней» нормы. Варьирование диаметра и длины плодов в оба года исследования входило в «нижнюю» область нормы. Коэффициент корреляции (r) диаметра и длины плодов в 2015 г. составил 0,62, в 2016 г. - 0,94. У большинства таксонов средние значения диаметра плодов превышали длину, плоды имели плоскоокруглую и округлую форму (индекс формы колебался в пределах 0,7-0,9). Исключением стал $V$. uliginosum, у которого плоды имели овальную форму (индекс формы равен 1,3). 
Показатели плодоношения видов и сортов Vaccinium

\begin{tabular}{|c|c|c|c|c|}
\hline \multirow{2}{*}{ Наименование таксона } & \multicolumn{2}{|c|}{ Размер плода, мм } & \multirow{2}{*}{$\begin{array}{c}\text { Масса } \\
100 \text { плодов, г }\end{array}$} & \multirow{2}{*}{$\begin{array}{c}\text { Количество плодов } \\
\text { в кисти, шт. }\end{array}$} \\
\hline & диаметр & длина & & \\
\hline \multirow{2}{*}{$V$. angustifolium } & $\underline{11,6 \pm 0,17}$ & $\underline{9,5 \pm 0,13}$ & $\underline{63,1 \pm 1,48}$ & $\underline{7,0 \pm 0,43}$ \\
\hline & $9,3 \pm 0,17$ & $\overline{7,7 \pm 0,07}$ & 42,5 & $\overline{6,6 \pm 0,60}$ \\
\hline \multirow{2}{*}{ V. corymbosum Bluecrop } & $\underline{8,8 \pm 0,22}$ & $\underline{7,6 \pm 0,14}$ & $\underline{35,2 \pm 2,38}$ & $\underline{4,7 \pm 0,24}$ \\
\hline & $\overline{11,9 \pm 0,20}$ & $\overline{9,6 \pm 0,21}$ & $\overline{74,6 \pm 1,49}$ & $\overline{6,0 \pm 0,71}$ \\
\hline \multirow{2}{*}{ V.c. Bluegold } & $\underline{11,9 \pm 0,17}$ & $\underline{8,7 \pm 0,11}$ & $\underline{70,9 \pm 0,66}$ & $\underline{9,2 \pm 0,90}$ \\
\hline & $\overline{12,0 \pm 0,12}$ & $\overline{8,4 \pm 0,10}$ & $\overline{72,7 \pm 1,16}$ & $\overline{7,3 \pm 0,54}$ \\
\hline \multirow{2}{*}{ V.c. Duke } & - & - & - & - \\
\hline & $11,1 \pm 0,14$ & $8,7 \pm 0,10$ & 66,8 & $6,9 \pm 0,65$ \\
\hline \multirow{2}{*}{$V . c$. Earlyblue } & - & - & - & - \\
\hline & $\overline{10,4 \pm 0,26}$ & $8,7 \pm 0,26$ & $\overline{55,3 \pm 11,88}$ & $\overline{5,4 \pm 0,34}$ \\
\hline \multirow{2}{*}{ V.c. Nelson } & - & - & - & - \\
\hline & $\overline{13,1 \pm 0,26}$ & $\overline{10,3 \pm 0,19}$ & 104,6 & $\overline{6,3 \pm 0,83}$ \\
\hline \multirow{2}{*}{ V.c. Patriot } & $\underline{12,8 \pm 0,18}$ & $\underline{10,9 \pm 0,17}$ & $\underline{113,9 \pm 2,35}$ & $\underline{6,3 \pm 0,40}$ \\
\hline & $12,8 \pm 0,12$ & $10,2 \pm 0,12$ & $104,0 \pm 4,29$ & $9,6 \pm 0,80$ \\
\hline \multirow{2}{*}{ V. c. Rancocas } & $\underline{9,6 \pm 0,21}$ & $\underline{8,1 \pm 0,15}$ & $\underline{42,2 \pm 1,15}$ & $\underline{5,1 \pm 0,36}$ \\
\hline & $\overline{9,7 \pm 0,30}$ & $\overline{7,8 \pm 0,27}$ & 43,8 & $\overline{5,3 \pm 1,20}$ \\
\hline \multirow{2}{*}{ V.c. Toro } & $\underline{12,9 \pm 0,20}$ & $\underline{10,3 \pm 0,13}$ & $\underline{106,8 \pm 2,33}$ & $\underline{5,3 \pm 0,47}$ \\
\hline & $\overline{12,3 \pm 0,10}$ & $\overline{9,7 \pm 0,09}$ & $85,3 \pm 3,68$ & $\overline{8,0 \pm 0,68}$ \\
\hline \multirow{2}{*}{$V . c . \times V . a$. Northcountry } & $\underline{9,9 \pm 0,19}$ & $\underline{7,8 \pm 0,14}$ & $\underline{41,1 \pm 1,18}$ & $14,6 \pm 1,07$ \\
\hline & $8,2 \pm 0,08$ & $6,5 \pm 0,09$ & $26,8 \pm 1,07$ & $6,3 \pm 0,73$ \\
\hline \multirow{2}{*}{ V. uliginosum } & $\underline{7,4 \pm 0,09}$ & $\underline{9,4 \pm 0,14}$ & $\underline{27,8 \pm 0,28}$ & $\underline{3,1 \pm 0,26}$ \\
\hline & $\overline{6,4 \pm 0,35}$ & $\ldots$ & 24,6 & $\overline{3,9 \pm 0,35}$ \\
\hline \multirow{2}{*}{ Среднее } & $\underline{10,6 \pm 0,71}$ & $\underline{9,0 \pm 0,42}$ & $\underline{62,6 \pm 11,57}$ & $\underline{6,9 \pm 1,26}$ \\
\hline & $\overline{10,6 \pm 0,63}$ & $\overline{8,8 \pm 0,39}$ & $\overline{63,7 \pm 8,41}$ & $\overline{6,5 \pm 0,45}$ \\
\hline \multirow{2}{*}{ Коэффициент вариации, \% } & $\underline{18,9}$ & $\underline{13,2}$ & $\underline{52,2}$ & $\underline{51,6}$ \\
\hline & $\overline{19,7}$ & $\overline{14,0}$ & $\overline{43,8}$ & 23,0 \\
\hline
\end{tabular}

Примечание. Над чертой - данные 2015 г., под чертой - 2016 г.

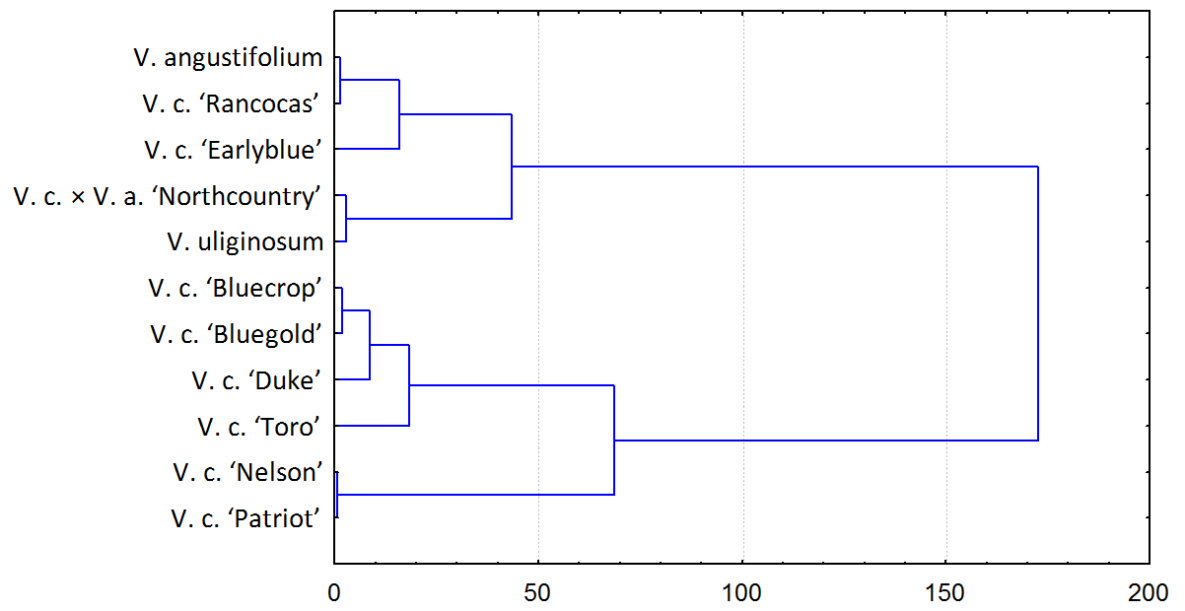

Рис. 2. Дендрограмма сходства видов и сортов Vaccinium на основе значений массы и размеров плодов. По горизонтали - расстояние Евклида; по вертикали - наименование таксона

Средние значения количества плодов в кисти изменялись в годы исследования от 3,1 до 14,6 шт. Уровень межсортовой изменчивости в 2015 г. был значительным, в 2016 г. входил в «нижнюю» норму варьирования. Наименьшим значением показателя отличался $V$. uliginosum, наибольшим $-V . c . \times V$. $a$. Northcountry (2015 г.) и V. c. Patriot (2016 г.).

На рисунке 3 изображены плоды некоторых голубик.

В 2015 г. у 4 таксонов был изучен выход воздушно-сухого сырья. Минимальное значение было отмечено у $V$. angustifolium $(14,4 \pm 0,09 \%$ ), максимальное - у $V$. c. $\times V$. a. Northcountry $(19,7 \pm 0,27 \%)$. Корреляция с массой плодов слабая отрицательная $(\mathrm{r}=-0,25)$. Между изученными таксонами различие статистически достоверно, кроме $V$. c. Patriot и $V$. uliginosum. Коэффициент вариации составил 13,4\%, что указывает на нижнюю норму варьирования признака. 

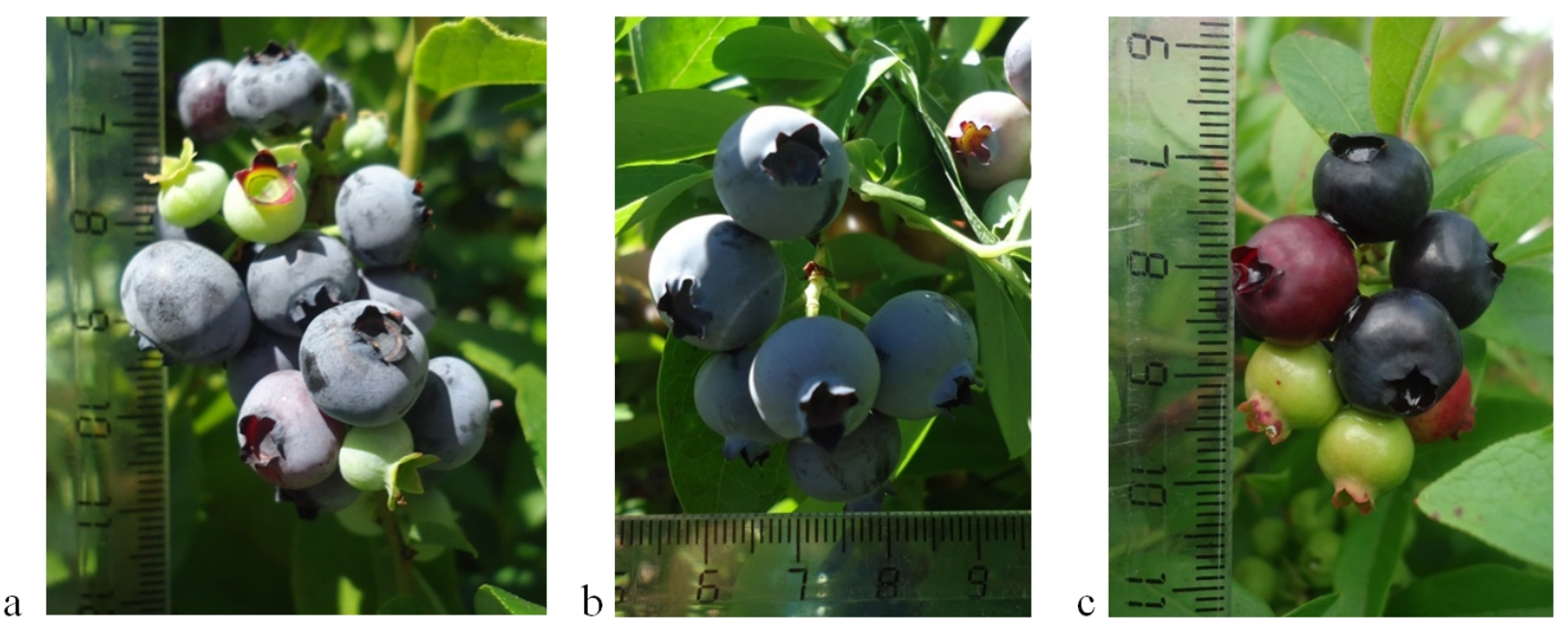

Рис. 3. Плоды голубики: $\mathrm{a}-V . c . \times V . a$. Northcountry, b $-V . c$. Patriot, c $-V$. angustifolium

Самой высокой урожайностью в 2015 г. характеризовалось растение $V$. angustifolium (995,8 г/куст). Далее в порядке снижения данного показателя следовали: V. c. Patriot (666,2 г), V. c. Northcountry (506,2 г), $V$. uliginosum $(289,7$ г), V. c. Bluegold (184,2 г). Менее 100 г плодов было собрано с растений $V$. c. Тоro $(76,9$ г), $V$. c. Rancocas $(43,4$ г) и $V$. c. Bluecrop $(35,1$ г). Низкая урожайность плодов может быть связана с недостатком влаги в вегетационный период текущего, а также предшествующего года. Поскольку растения недавно вступили в генеративную фазу, их репродуктивные способности реализуются неполностью, и, следовательно, в последующие годы следует ожидать повышение урожайности.

Исследование по содержанию флавоноидов и аскорбиновой кислоты в плодах голубики проводили в 2015 г., который был менее засушливым по сравнению с 2016 г. Из флавоноидных соединений, часто встречающихся в плодах, следует отметить рутин. Самое высокое значение данного показателя наблюдалось у $V$. uliginosum, самое низкое - у сорта $V$. c. Patriot. Среднее значение показателя было характерно для плодов $V$. angustifolium и межвидового гибрида $V . c . \times V$. a. Northcountry (рис. 4). Количество рутина в плодах $V$. uliginosum было больше, чем в плодах $V$. c. Patriot в 2,5 раза, V. c. $\times V$. a. Northcountry - в 1,6 раза, $V$. angustifolium - в 1,4 раза. В целом, у изученных видов и сортов голубики содержание рутина в ягодах варьировало от 1,79 до 4,53 мг/100г сырой массы. По содержанию рутина в плодах между $V$. angustifolium и межвидового гибрида $V . c . \times V$. a. Northcountry статистически значимой разницы не обнаружено $(\mathrm{P}>0,05)$. В плодах голубики обыкновенной, произрастающей на территории Красноярского края, выявлено аналогичное количество рутина - 5,15 мг\% [26].

Не менее важной компонентой биохимического состава плодов голубики являются антоцианы. Проведенный анализ показал, что содержание антоцианов в плодах изученных видов и сортов Vaccinium варьировало от 18,1 до 78,2 мг/100 г сырой массы (рис. 5). В результате проведенных исследований выяснили, что наибольшее содержание антоцианов в плодах наблюдалось у $V$. angustifolium, а наименьшее - в плодах голубики сорта Patriot. Плоды $V$. uliginosum и межвидового гибрида $V$. $c . \times V$. $a$. Northcountry содержали среднее количество антоцианов - 28,0 и 29,1 мг/100 г соответственно (Р>0,05). V. angustifolium характеризуется более темной окраской ягод. В плодах голубики, антоцианы сосредоточенны большей частью в кожице [27]. По мере созревания ягод наблюдается увеличение количественного содержания антоцианов.

Сопоставляя собственные данные с результатами других исследователей, можно заключить, что в плодах изученных нами видов и сортов голубики накапливалось столько же антоцианов, как у голубики обыкновенной, черноплодной и щитковой, выращиваемых в Ботаническом саду ННГУ [28], но больше, чем в плодах клюквы болотной [29].

Среди водорастворимых витаминов наиболее известна аскорбиновая кислота. Содержание аскорбиновой кислоты в плодах растений голубики изменялось от 9,07 до 29,9 мг/100 г сырой массы (рис. 6). Наибольшее количество аскорбиновой кислоты наблюдалось в плодах голубики межвидового гибрида $V$. $c$. $\times$ $V$. a. Northcountry, наименьшее, в 3,3 раза - в плодах сорта $V$. c. Patriot. Средние показатели содержания витамина С обнаружены в плодах $V$. uliginosum и $V$. angustifolium. В плодах $V$. angustifolium содержание аскорбиновой кислоты в 2 раза, $V$. uliginosum - в 1,6 раза меньше, чем в плодах сорта $V . c . \times V$. $a$. Northcountry. По содержанию аскорбиновой кислоты между изученными видами и сортами голубики обнаружена статистически значимая разница. 


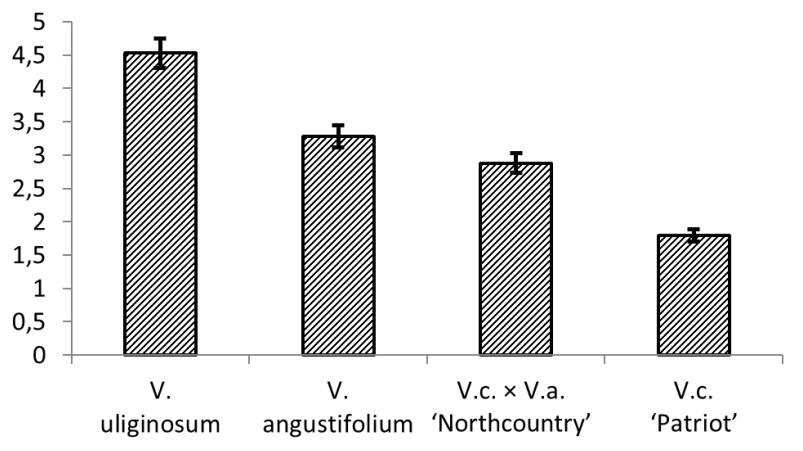

Рис. 4. Содержание рутина в ягодах растений Vaccinium. По горизонтали - виды и сорта Vaccinium; по вертикали - количество рутина, мг/100 г сырой массы

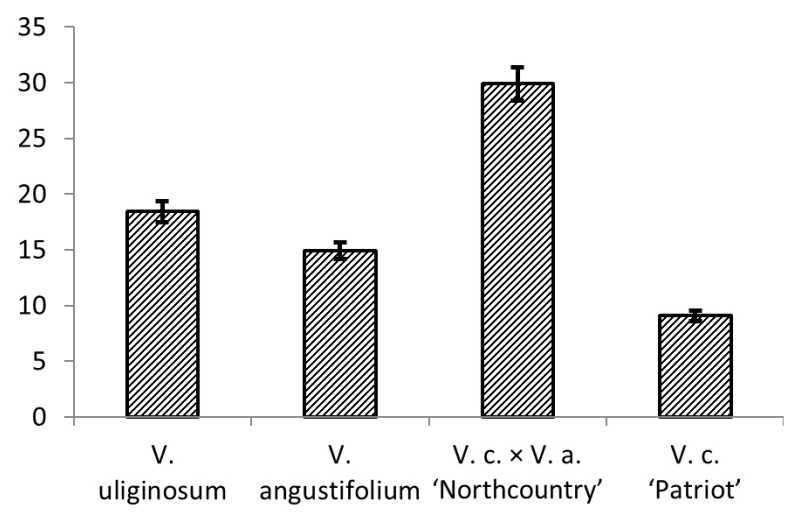

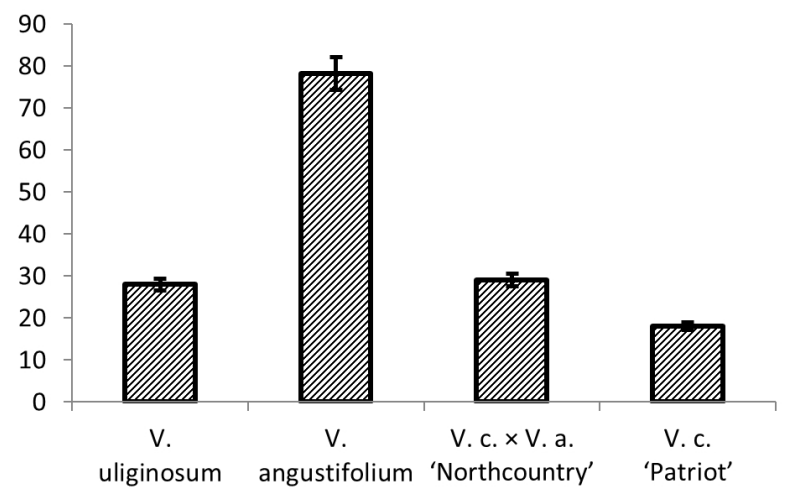

Рис. 5. Содержание антоцианов в ягодах растений Vaccinium. По горизонтали - виды и сорта Vaccinium; по вертикали - количество антоцианов, мг/100 г сырой массы

Рис. 6. Содержание аскорбиновой кислоты в ягодах растений Vaccinium. По горизонтали виды и сорта Vaccinium; по вертикали количество аскорбиновой кислоты, мг/100 г сырой массы

Полученные данные сходны с результатами исследователей из Нижегородского государственного университета им. Н.И. Лобачевского, которые изучали содержание аскорбиновой кислоты в плодах голубики обыкновенной, щитковой и черноплодной [28].

В работе [4] отмечено, что у различных сортов голубики высокой минимальное значение аскорбиновой кислоты соответствовало 9,6, максимальное - 18,6 мг/100 г сырой массы [30], у голубики обыкновенной составляло 10,29 мг/100 г сырой массы.

\section{Выводы}

Таким образом, 11 видов и сортов голубики прошли первичную интродукцию в условиях Республики Марий Эл. В годы исследования они характеризовались массой 100 плодов от 24,6 до 113,9 г и разделены на 2 группы: с крупными плодами - V. c. Patriot, $V$. c. Nelson, V. c. Toro, V. c. Duke, V. c. Bluegold, V.c. Bluecrop; с мелкими плодами - V. uliginosum, $V . c . \times V$. a. Northcountry, $V . c$. Earlyblue, $V . c$. Rancocas, $V$. angustifolium. Большинство изученных голубик в более засушливых условиях 2016 г. характеризовались меньшей массой и размерами плодов по сравнению с 2015 г. Наименьшим количеством плодов в кисти отличался $V$. uliginosum, наибольшим - V.c. $\times V$. a. Northcountry и $V . c$. Patriot. В 2015 г. растение $V$. angustifolium отличалось самой высокой урожайностью. Далее в порядке снижения показателя следовали $V$. $c$. Рatriot, $V . c$. Northcountry, V. uliginosum, $V$. c. Bluegold. Наименьший урожай был собран с растений $V$. $c$. Тоro, $V$. c. Rancocas и V. с. Bluecrop.

Изученные представители рода Vaccinium в условиях БСИ ПГТУ характеризуются меньшими размерами и массой плодов по сравнению с литературными данными, что обусловлено, по нашему мнению, влиянием абиотических факторов. Повысить продуктивность возможно путем улучшения агротехнических мероприятий - увеличением поливов и внесением удобрений. Поскольку обследованные растения недавно вступили в генеративную фазу, их репродуктивные способности реализовались пока неполностью. 
Однако содержание биологически активных веществ в плодах изученных видов и сортов Vaccinium оставалось на высоком уровне. Диапазон содержания (мг/100 г сырой массы) рутина составил от 1,79 до 4,53, антоцианов - от 18,1 до 78,2, аскорбиновой кислоты - от 9,07 до 29,9. Наибольшее количество рутина выявлено у $V$. uliginosum, антоцианов - у $V$. angustifolium, аскорбиновой кислоты - у $V$. $c . \times V$. $a$. Northcountry. Сорт $V . c$. Patriot, формирующий наиболее крупные плоды, содержал наименьшее количество рутина, антоцианов и аскорбиновой кислоты по сравнению с другими видами и сортами.

Плоды голубики представляют практическую ценность в качестве пищевого ресурса. Полученные данные могут быть использованы при организации плантационного возделывания видов и сортов голубики в условиях Волго-Вятского региона.

\section{Список литературь}

1. Trehane J. Blueberries, cranberries, and other vacciniums. Portland, 2009. 272 p.

2. Paprsteina F., Ludvikova J., Sedlak J. Evaluation of a germplasm collection of highbush blueberry (Vaccinium corymbosum L.) in the Czech Republic //Acta Horticulturae. 2009. Vol. 810. Pp. 97-102.

3. Bădescu C., Bădescu C., Delian E., Bădescu A. Productivity characteristics of 15-to 40-year-old highbush blueberry in Romanian submountaine areas // Acta Horticulturae. 2009. Vol. 810. Pp. 495-500.

4. Брыксин Д.М., Кирина И.Б., Бочарова Т.Е. Сравнительная оценка качества ягод голубики высокой в условиях ЦЧР // Вестник БГСХА. 2012. №5. С. 10-12.

5. Retamales J.B., Hancock J.F. Blueberries (Crop production science in horticulture). Wallingford, 2012. 323 p.

6. Горбунов А.Б., Симагин В.С., Фотев Ю.В. и др. Интродукция нетрадиционных плодовых, ягодных и овощных растений в Западной Сибири. Новосибирск, 2013. 290 с.

7. Smolarz K., Pluta S. Cultivation of the high-bush blueberry in Poland // Acta Horticulturae. 2014. Vol. 1017. Pp. 199-204.

8. Starast M., Paal T., Vool E., Karp K., Albert T., Moor U. The productivity of some blueberry cultivars under Estonian conditions // Acta Horticulturae. 2009. Vol. 810. Pp. 103-108.

9. Рупасова Ж.А., Яковлев А.П., Лиштван И.И., Кудряшова О.А. Генотипические особенности параметров плодоношения таксонов рода Vaccinium в опытной культуре на выбывшем из промышленной эксплуатации торфяном месторождении севера Беларуси // Вестник Полесского государственного университета. Серия природоведческих наук. 2011. № 1. С. 43-46.

10. Sterne D., Liepniece M., Abolins M. Productivity of some blueberry cultivars under Latvia conditions // Acta Horticulturae. 2012. Vol. 926. Pp.185-190.

11. Paulouski M. Blueberry culture in Belarus // Acta Horticulturae. 2014. Vol. 1017. Pp. 159-162.

12. Конобеева А.Б. Брусничные в Центрально-Черноземном регионе. Мичуринск, 2007. 230 с.

13. Тяк Г.В., Курлович Л.Е., Макеев В.А., Макеева Г.Ю., Тяк А. В. Выращивание клюквы и голубики на землях лесного фонда, вышедших из-под торфодобычи // Лесохозяйственная информация. 2015. № 1. С. $72-78$.

14. Методы анализа витаминов: практикум / сост. Г.Н. Чупахина, П.В. Масленников. Калининград, 2004. 36 с.

15. Титок В., Веевник А., Павловский Н. Голубика высокорослая - инновационная культура премиум-класса // Наука и инновации. 2012. № 6 (112). С. 25-27.

16. Шаталов Д.О., Кедик С.А., Иванов И.С., Бирюлин С.И. Антиоксиданты, как перспектива снижения заболеваний системы кровообращения, возникающих по причине ухудшающейся экологической обстановки // Вестник МИТХТ. Серия: социально-гуманитарные науки и экология. 2015. № 3. С. 52-58.

17. Жукова Л.А., Ведерникова О.П., Быченко Т.М., Османова Г.О. Лекарственные растения: разнообразие жизненных форм. Йошкар-Ола, 2015. 168 с.

18. Лазарева С.М., Мухаметова С.В., Сухарева Л.В. и др. Ботанический сад-институт ПГТУ: история, коллекции, исследования. Йошкар-Ола, 2014. 108 с.

19. Методы биохимического исследования растений / под ред. А.И. Ермакова. Л., 1972. 456 с.

20. Srivastava A., Akoh C.C., Yi W., Fischer J., Krewer G. Effect of storage conditions on the biological activity of phenolic compounds of blueberry extract packed in glass bottles // Journal of Agricultural and Food Chemistry. 2007. Vol. 7. Рp. 2705-2713.

21. Шапиро Д.К. Практикум по биологической химии / под ред. акад. АН БССР А.С. Вечера. Минск, 1976. 288 с.

22. Зайцев Г.Н. Математика в экспериментальной ботанике. М., 1990. 296 с.

23. Лазарева С.М. Использование методик обработки данных фенологических наблюдений (на примере представителей семейства Pinaceae Lindl.) // Известия Иркутского гос. ун-та. Сер. Биология. Экология. 2011. №2. C. $56-65$.

24. Лосев А.П. Практикум по агрометеорологическому обеспечению растениеводства. СПб., 1994. 244 с.

25. Мухаметова С.В., Акшикова Н.А. Плодоношение представителей рода Vaccinium в республике Марий Эл // Вестник ПГТУ. Сер. Лес. Экология. Природопользование. 2016. № 4 (32). С. $78-88$.

26. Величко Н.А., Берикашвили 3.Н. Исследование химического состава ягод голубики обыкновенной и разработка рецептур напитков на ее основе // Вестник КрасГАУ. 2016. № 7. С. 126-131.

27. Сенчук Г.В., Борух И.Ф. Дикорастущие ягоды Белоруссии // Растительные ресурсы. 1976. № 1. С. $113-117$. 
28. Павлова Е.Е., Березина Е.В., Мишукова И.В., Брилкина А.А. Анализ содержания фенольных соединений и аскорбиновой кислоты у различных видов голубики (Vaccinium L.) в периоды цветения и плодоношения // Вестник Нижегородского ун-та им. Н.И. Лобачевского. 2012. № 2 (3). С. 222-229.

29. Березина Е.В., Брылкина А.А., Веселов А.П. Содержание фенольных соединений в листьях и плодах Vaccinium vitis-idaea и Oxycoccus palustris (Ericaceae) в разные периоды вегетации // Растительные ресурсы. 2015. №1. С. 88-97.

30. Яковлев А.П., Рупасова Ж.А., Барков С.П., Бондаренко Н.В., Демченко В.В., Белышева Л.Л. Влияние минерального питания на урожайность и качество плодов голубики Vaccinium uliginosum L. на севере Беларуси // Веснік Віцебскага дзяржаўнага ўніверсітэта. 1999. № 2 (12). С. 96-101.

Поступило в редакиию 3 февраля 2017 г.

После переработки 9 марта 2017 г.

Mukhametova S.V..$^{I^{*}}$, Skochilova E.A. ${ }^{2}$, Protasov D.V. ${ }^{2}$ FRUITING PARAMETERS AND CONTENT OF FLAVONOIDS AND ASCORBIC ACID IN BLUEBERRY (VACCINIUM) FRUITS

${ }^{1}$ Botanical garden-institute of Volga State University of Technology, Yoshkar-Ola, Mira st., 2B, 424030 (Russia), e-mail: MuhametovaSV@volgatech.net

${ }^{2}$ Mari State University, Yoshkar-Ola, Osipenko st.t, 60, 424000 (Russia), e-mail: skochilova@inbox.ru

The research results of fruiting parameters and content of flavonoids and ascorbic acid in the fruits of Vaccinium species and varieties in the Mari El Republic are presented. The objects of our research were $V$. uliginosum L., $V$. angustifolium Ait., 8 varieties of $V$. corymbosum L. and $V . a . \times V . c$. Northcountry. Values of blueberry fruits diameter in research years varied from 6,4 to $13,1 \mathrm{~mm}$, fruits length - from 6,5 to $10,3 \mathrm{~mm}, 100$ fruit weight - from 24,6 to $113,9 \mathrm{~g}$. The studied species and varieties were divided on 2 groups: large-fruited $-V$. c. Patriot, $V . c$. Nelson, $V . c$. Toro, V. c. Duke, V. c. Bluegold, $V$. $c$. Bluecrop; and small-fruited $-V$. uliginosum, $V . c . \times V . a$. Northcountry, $V . c$. Earlyblue, $V . c$. Rancocas, $V$. angustifolium. The studied Vaccinium representatives are characterized by smaller size and weight of fruits compared with the literature data. The content of biologically active substances in Vaccinium fruits remained at a high level. The range of content $(\mathrm{mg} / 100 \mathrm{~g}$ wet weight) of ruthin was from 1,79 to 4,53 , anthocyanins - from 18.1 to 78.2 , ascorbic acid - from 9,07 to 29,9 . The largest amount of ruthin was found in fruits of $V$. uliginosum, anthocyanins $-V$. angustifolium, ascorbic acid $-V . c . \times V . a$. Northcountry. V. c. Patriot contained the least amount of biochemical compounds.

Keywords: blueberry, Vaccinium, fruiting, flavonoids, ascorbic acid.

\footnotetext{
${ }^{*}$ Corresponding author.
} 


\section{References}

1. Trehane J. Blueberries, cranberries, and other vacciniums, Portland, 2009, $272 \mathrm{p}$.

2. Paprsteina F., Ludvikova J., Sedlak J. Acta Horticulturae, 2009, vol. 810, pp. 97-102.

3. Bădescu C., Bădescu C., Delian E., Bădescu A. Acta Horticulturae, 2009, vol. 810, pp. 495-500.

4. Bryksin D.M., Kirina I.B., Bocharova T.E. Vestnik of the Bryansk State Agricultural Academy, 2012, no 5, pp. 10-12. (in Russ.).

5. Retamales J.B., Hancock J.F. Blueberries (Crop production science in horticulture), Wallingford, 2012. 323 p.

6. Gorbunov A.B., Simagin V.S., Fotev Ju.V. et al. Introdukciya netradicionnyh plodovyh, yagodnyh $i$ ovoshchnyh rasteniy $v$ Zapadnoy Sibiri. [Introduction of not traditional fruit, berry and vegetable plants in West Siberia]. Novosibirsk, 2013, 290 p. (in Russ.).

7. Smolarz K., Pluta S. Acta Horticulturae, 2014, vol. 1017, pp. 199-204.

8. Starast M., Paal T., Vool E., Karp K., Albert T., Moor U. Acta Horticulturae, 2009, vol. 810, pp.103-108.

9. Rupasova Zh.A., Yakovlev A.P., Lishtvan I.I., Kudryashova O.A. Bulletin of Palesky state university. Series in natural sciences, 2011, no. 1, pp. 43-46. (in Russ.).

10. Sterne D., Liepniece M., Abolins M. Acta Horticulturae, 2012, vol. 926, pp. 185-190.

11. Paulouski M. Acta Horticulturae, 2014, vol. 1017, pp. 159-162.

12. Konobeeva A.B. Brusnichnye v Centralno-Chernozemnom regione [Vacciniaceae in the Central Black Earth region]. Michurinsk, 2007, 230 p. (in Russ.).

13. Tyak G.V., Kurlovich L.E., Makeev V.A., Makeeva G.U., Tyak A.V. Lesokhoziaistvennaia informatsiia, 2015, no. 1, pp. 72-78. (in Russ.).

14. Chupakhina G.N., Maslennikov P.V. Metody analiza vitaminov [Methods of vitamins analysis: Workshop]. Kaliningrad, 2004, 36 p. (in Russ.).

15. Titok V., Veevnik A., Pavlovskii N. Nauka i innovatsii, 2012, no. 6 (112), pp. 25-27. (in Russ.).

16. Shatalov D.O., Kedik S.A., Ivanov I.S., Biriulin S.I. Vestnik MITKhT. Seriia: sotsial'no-gumanitarnye nauki $i$ ekologiia, 2015, no. 3, pp. 52-58. (in Russ.).

17. Zhukova L.A., Vedernikova O.P., Bychenko T.M., Osmanova G.O. Lekarstvennye rasteniia: raznoobrazie zhiznennykh form. [Medicinal plants: a variety of life forms]. Yoshkar-Ola, 2015, 168 p. (in Russ.).

18. Lazareva S.M., Mukhametova S.V., Sukhareva L.V. et al. Botanicheskii sad-institut PGTU: istoriia, kollektsii, issledovaniia. [Botanical garden-institute PSTU: history, collections, research]. Yoshkar-Ola, 2014, 108 p. (in Russ.).

19. Metody biokhimicheskogo issledovaniia rastenii. [Methods of biochemical research of plants]. Ed. A.I. Ermakov. Leningrad, 1972, 456 p. (in Russ.).

20. Srivastava A., Akoh C. C., Yi W., Fischer J., Krewer G. Journal of Agricultural and Food Chemistry, 2007, vol. 7, pp. 2705-2713.

21. Shapiro D.K. Praktikum po biologicheskoi khimii. [Workshop on Biological Chemistry]. Minsk, 1976, 288 p. (in Russ.).

22. Zaitsev G.N. Matematika v eksperimental'noi botanike. [Mathematics in experimental botany]. Moscow, 1990,296 p. (in Russ.).

23. Lazareva S.M. Izvestiia Irkutskogo gosudarstvennogo universiteta. Seriia «Biologiia. Ekologiia», 2011, no. 2, pp. 5665. (in Russ).

24. Losev A.P. Praktikum po agrometeorologicheskomu obespecheniiu rastenievodstva. [Workshop on agrometeorological support of crop production]. St. Petersburg, 1994. 244 p. (in Russ).

25. Mukhametova S.V., Akshikova N.A. Vestnik PGTU. Ser.: Les. Ekologiia. Prirodopol'zovanie, 2016, no. 4(32), pp. 78-88. (in Russ).

26. Velichko N.A., Berikashvili Z.N. Vestnik KrasGAU, 2016, no. 7, pp. 126-131. (in Russ).

27. Senchuk G.V., Borukh I.F. Rastitel'nye resursy, 1976, no. 1, pp. 113-117. (in Russ).

28. Pavlova E.E., Berezina E.V., Mishukova I.V., Brilkina A.A. Vestnik Nizhegorodskogo universiteta im. N.I. Lobachevskogo, 2012, no. 2(3), pp. 222-229. (in Russ).

29. Berezina E.V., Brylkina A.A., Veselov A.P. Rastitel'nye resursy, 2015, no. 1, pp. 88-97. (in Russ).

30. Iakovlev A.P., Rupasova Zh.A., Barkov S.P., Bondarenko N.V., Demchenko V.V., Belysheva L.L. Vesnik Vicebskaga dzjarzhawnaga wniversitjeta, 1999, no. 2(12), pp. 96-101. (in Russ). 
